\title{
The UK's reliance on imports from the EU for nutrition security
}

\author{
S. Whybrow ${ }^{1}$, H. Clark ${ }^{2}$, H. R. de Ruiter ${ }^{3,4}$ and J.I. Macdiarmid ${ }^{1}$ \\ ${ }^{1}$ Rowett Institute, University of Aberdeen, Aberdeen AB25 2ZD, \\ ${ }^{2}$ Institute of Applied Health Services, University of Aberdeen, Aberdeen AB25 2ZD, \\ ${ }^{3}$ Institute of Biological and Environmental Sciences, University of Aberdeen, AB24 $2 T Z$ and \\ ${ }^{4}$ Information and Computational Sciences Group, The James Hutton Institute, Aberdeen, AB15 8QH
}

The UK relies on food imports; around $40 \%$ by weight and $31 \%$ by monetary value is imported, mostly directly, or indirectly, from countries within the European Union (EU) ${ }^{(1)}$. Disruption of this supply may occur, depending on what trading agreements are in place at the end of the Brexit transition period. The UK relies more on imports of some food groups than others, and this may have implications for nutrition security.

This study investigated where the UK currently gets its energy and nutrients from, the proportions produced domestically, imported from the EU and imported from the rest of the world excluding the EU (World).

FAO Food Balance Sheet (FBS) data for the supply of food commodities and trade data FAOSTAT detailed trade matrix data for 2013 (the most recent available), for 96 food commodities were obtained from the FAOSTAT and linked to allow the proportion of each commodity group imported from the EU, and World to be calculated. Food exports were subtracted from domestic supply, World and EU imports in proportion. Supply of energy and nutrients was estimated by matching FBS food groups to food composition data ${ }^{(2)}$. Population weighted energy and nutrient requirements were calculated from dietary reference values and recommendations, and the UK demographic in $2013^{(2)}$. Commodities were adjusted for edible portion and food waste to estimate the supply of nutrients available.

Except for protein, where domestic production alone almost met requirements, calcium and vitamin B12, the UK was dependent on EU imports to meet requirements for energy, carbohydrate, fat and nutrients - including some where intakes are marginal in some population groups.

The proportion of the weighted requirements from domestic production, imports from the EU and imports from the rest of the World were: Protein: 81.6\%, 53.0\%, 18.4\%; Ca: 90.5\%, 52.7\%, 10.9\%; Vit. B12: 259.5\%, 172.3\%, 55.3\%; Energy: 47.6\%, 35.3\%, 16.7\%; CHO: 52.1\%, 33.2\%, 21.8\%; Fat: 49.7\%, 42.6\%, 13.3\%; Mg: 48.3\%, 35.7\%, 19.4\%; Fe: $53.2 \%$, 39.8\%, 22.5\%; Zn: $57.1 \%$, $37.5 \%, 13.5 \%$ and Vitamin A (Retinol Equivalent): $61.2 \%, 57.9 \%, 11.4 \%$.

Post Brexit transition period trade agreements could affect the UK food supply in many ways, including changing food prices, demand for exports, and availability of migrant workers. Nutrition security should be considered along with economic and food security to ensure the adequacy of nutrient supply, that the UK has long enjoyed, continues.

1. Lang T \& McKee M (2018) J. Public Health, 40, e608-e610.

2. Macdiarmid J, Clark H, Whybrow S et al. (2018) PLoS One 13, e0192649. 